\title{
Occupational asthma in France: a 1-yr report of the Observatoire National de Asthmes Professionnels project
}

\author{
M.C. Kopferschmitt-Kubler*, J. Ameille\#, E. Popin*, A. Calastreng-Crinquand", D. Vervloet*, \\ M.C. Bayeux-Dunglas", G. Pauli*, and members of Observatoire National de Asthmes \\ Professionnels Group
}

Occupational asthma in France: a 1-yr report of the Observatoire National de Asthmes Professionnels project. M.C. Kopferschmitt-Kubler, J. Ameille, E. Popin, A. Calastreng-Crinquand, D. Vervloet, M.C. Bayeux-Dunglas, G. Pauli, and members of Observatoire National de Asthmes Professionnels Group. (C) ERS Journals Ltd 2002. ABSTRACT: Observatoire National des Asthmes Professionnels (ONAP) was created in 1996 by two French professional societies to estimate the incidence of occupational asthma and to promote preventive measures against it.

Occupational and chest physicians were asked to report newly diagnosed cases of work-related asthma and reactive airway dysfunction syndrome (RADS), the information collected included age, sex, occupation, suspected causal agents and diagnostic methods.

In $1997,82.3 \%$ of 559 cases reported (64\% males, mean age $36 \pm 13$ yrs) involved occupational asthma, $4.7 \%$ RADS and $12.7 \%$ atypical asthma syndromes. Incidence rates (expressed as number of cases per million workers) showed a regional variation that ranged from 4 to 73 (national mean: 25.7). The most frequently suspected agents were flour $(23.3 \%)$, followed by isocyanates $(16.6 \%)$, latex $(7.5 \%)$, aldehydes $(5.5 \%)$, and persulphates $(4.1 \%)$. Occupations at risk were bakers $(23.9 \%)$, healthcare workers $(12 \%)$, painters $(9.1 \%)$, hairdressers $(5.2 \%)$, wood industry workers $(4.8 \%)$ and cleaners $(3.5 \%)$. These results are compared to those of other systems set up in Europe and North America.

Because of the considerable bias inherent in a surveillance system based on voluntary, reporting, the number of occupational asthma cases reported is probably lower than the real incidence. Nevertheless, the French National Observatory for Occupational Asthma encourages physician awareness of occupational asthma and provides an estimate of its incidence and aetiologies in France.

Eur Respir J 2002; 19: 84-89.
*Société de Pneumologie de Langue Française and " Société Française de Médecine du Travail, Paris, France.

Correspondence: G. Pauli, Service de Pneumologie, Hôpital Lyautey, Hôpitaux Universitaires de Strasbourg, B.P 426, 67091 Strasbourg Cedex, France. Fax: 33388116351

Keywords: Occupational asthma reactive airway dysfunction syndrome surveillance

Received: December 62000 Accepted after revision September 17 2001

The work was supported by grants from the French Ministère de l'Emploi et de la Solidarité, the Caisse Nationale d'Assurance Maladie des Travailleurs Salariés, the Comité National des Maladies Respiratoires, the Comité Départemental des Maladies Respiratoires du Bas-Rhin, and Les Hôpitaux Universitaires de Strasbourg. It was also supported by the Glaxo Wellcome Laboratory.
Few countries have satisfactory means of monitoring the occurrence of occupational asthma, although such surveillance is a necessary precondition for effective prevention measures. In France, the only sources available are the national statistics of the national workers' compensation insurance scheme, but taking into account the noncompulsory character of claims, occupational asthma in France has certainly been underreported $[1,2]$. In 1995, a working committee in environmental pathology was set up by members of two professional associations, the Société de Pneumologie de Langue Française (French Lung Society, or SPLF) and the Société Française de Médecine du Travail (French Occupational Medicine Society, or SFMT). One of its aims was to create "ONAP" (Observatoire National des Asthmes Professionnels, or the National Observatory for Occupational Asthma) for the voluntary reporting of occupational asthma by chest and occupational physicians. A detailed proposal was submitted to the Commission Nationale de 1'Informatique et des Libertes (CNIL),
Committee for Computer Privacy Rights and approved in April 1996. ONAP's objectives were to estimate the incidence of occupational asthma and its regional distribution, the frequency of various causal agents, the validity of the methods used to assess occupational asthma diagnosis, and to promote early recognition of new aetiologies.

The present study is a descriptive analysis of the results of the first full year of sampling (1997). The reported cases are compared with those from earlier voluntary schemes introduced for the surveillance of occupational asthma in other countries [3-7] and those from mandatory surveillance programmes [8, 9].

Material and methods

\section{Recruitment}

After obtaining CNIL approval, the coordinators for the SPLF and SFMT began to involve their 
members in this survey of work-related asthma throughout 1996, sending them letters with the questionnaire.

The SPLF solicited chest physicians and allergists by three such letters as well as inserts in specialized national respiratory journals. To maximize participation, the protocol was also presented at national and regional meetings.

The SFMT obtained the participation of the 25 university hospital departments of occupational medicine, across France. These departments are reference centres to which occupational physicians refer patients with suspected occupational diseases. The network was also expanded to include the physicians who determine statutory compensation for occupational diseases in the Ile-de-France region (Greater Paris Metropolitan Area). Finally, for SFMT, 59 corresponding members gave information to ONAP: they were physicians working in occupational medicine departments, occupational physicians with senior positions in large occupational health services or officers in regional occupational medicine societies, and a few were chest physicians working in university hospitals.

\section{Procedure}

The ONAP questionnaire is one A4 page long. The first items referred to the physician reporting the case (name, address, specialization, private or hospitalbased practice). The following, items concerned the patient first three letters of name and forename, age, sex (these four items together enabled the exclusion of identical cases), region of workplace, type of health insurance, occupation and work location. Possible diagnoses were classified into the following categories: occupational asthma (occurring after a latency period of exposure to high or low molecular weight agents), reactive airway dysfunction syndrome (RADS) (occurring after inhalation of high concentrations of nonspecific irritants), and atypical asthma syndrome (such as spasmodic cough, atypical dyspnoea occurring in the work environment). The possible methods of diagnosis were then listed: positive clinical history of work-related symptoms, positive work-related modifications of peak expiratory flow rate (PEFR) or spirometry, positive nonspecific hyperresponsiveness, positive response to skin tests and positive immunoglobulin (Ig)-E levels to the aetiological agent, positive nasal or bronchial challenge tests to the suspected agent. For each item the physician was asked to choose between three answers: yes, no or not done. As there is no satisfactory marker of occupational asthma, physicians were also asked to assess the accuracy of the diagnosis on a 3-point scale (certainly, probably or possibly linked to work). Offending agents were classified into six main categories: isocyanates, flour, plant products (except flour), animal products, chemicals (other than isocyanates), and metals. Two further categories concerned substances that were not clearly identified substances and multiple offending agents. When identified, the offending agent was noted in full. The last item asked whether the patient had made any claim of occupational asthma to the national workers' compensation insurance board (in France, doctors are not required to report cases).

The information from each questionnaire was entered into a database. Place of residence was coded according to standard administrative region, and occupation according to the International Standard Classification of Occupations (ISCO 88, Geneva 1991) and to the official French nomenclature of activities and products (published in the Journal Officiel, November 1999).

\section{Rates}

Data from the Institut National de la Statistique et des Etudes Economiques (INSEE) were used to estimate incidence rates of occupational asthma (per million workers) in the working population of France as a whole and also according to regions of residence.

\section{Results}

Cases reported to Observatoire National des Asthmes Professionnels

Overall, 559 cases were reported to the ONAP survey; $460(82.3 \%)$ were typical occupational asthma, 26 RADS (4.7\%), and 71 atypical asthma syndrome $(12.7 \%)$. Patients' sex was stated in $99.8 \%$ of the reported cases: $64.2 \%$ were males, and $35.6 \%$ females, but the ratio varied with occupation and aetiological category. Males accounted for a predominant share of the workers exposed to isocyanates (74\%) and to flour $(93 \%)$, while more females were exposed to animals $(60 \%)$. The mean age was $36 \pm 13$ yrs. The age distribution was as follows: aged 20-29 yrs: 27\%; $30-39$ yrs: $26 \%$; 40-49 yrs: $22 \%$; 50-59 yrs: $17 \%$.

\section{Suspected agents and occupations}

Agents. Figure 1 summarizes the results into eight categories: $46.5 \%$ of the suspected agents had biological sources, while $41.2 \%$ came from isocyanates, other chemicals and metals. In $8.1 \%$ of the cases, the agents were not clearly identified. When more than one offending agent was found $(4.2 \%$ of the cases), the most frequent association was flour and alpha-amylase $(46 \%)$.

All the aetiologies of occupational asthma were then analysed separately. In all, 133 different agents were reported, with flour, isocyanates and latex the most common. The 14 most frequent aetiologies are reported in table 1. Among 26 RADS reported, four occurred after acids inhalation, three after chlorine inhalation and three after isocyanates inhalation. Atypical syndromes (71 cases) were mainly observed with flour (11 cases), isocyanates (10 cases), latex (seven cases), persulphates (seven cases).

Details concerning the associations between occupations and suspected aetiologies have been obtained 


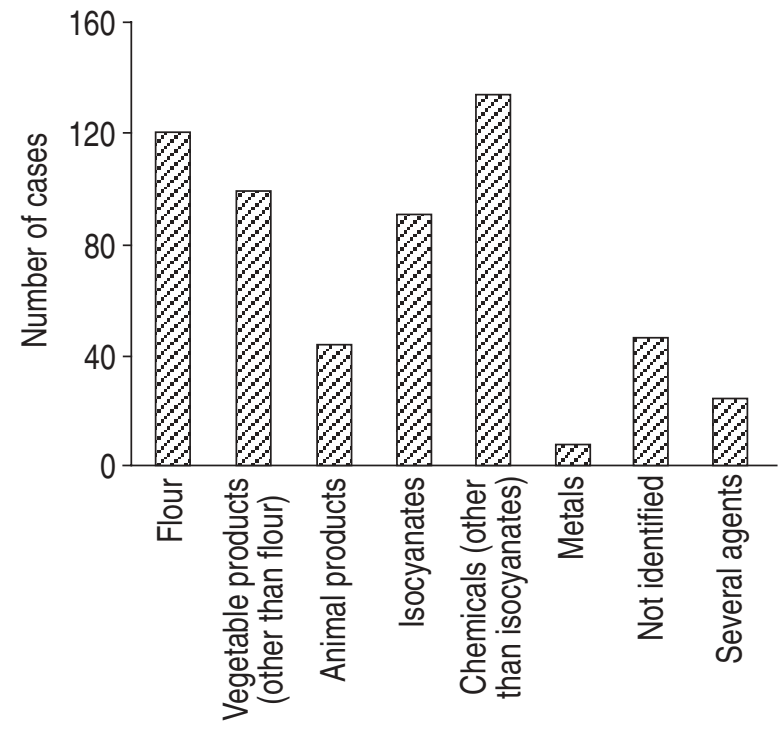

Aetiological agents

Fig. 1.-Frequency of the main categories of suspected agents in cases reported by the Observatoire National des Asthmes Professionnels (ONAP) in 1997.

for all cases (the full data concerning association between occupation and suspected aetiologies can be supplied to interested readers).

Occupations. Occupations were classified into activity sectors, for example, healthcare (physicians, nurses, dentists, etc.); painters, hairdressers and bakers were each separate categories. The most frequently represented occupations were bakers, healthcare workers and painters (fig. 2).

Diagnosis. Physicians considered that their diagnosis was correct in nearly $80 \%$ of the cases $(58 \%$ answered "certainly" and 20.8\% "probably"). A positive clinical history of work-related symptoms was found in $92.1 \%$ of the cases.

Objective measurements of work-related symptoms

Table 1.-Major suspected aetiologies in cases reported by the Observatoire National des Asthmes Professionnels (ONAP) in 1997

\begin{tabular}{lcc}
\hline Substances & Absolute number & Percentage \\
\hline Flour & 130 & 23.3 \\
Isocyanates & 93 & 16.6 \\
Latex & 42 & 7.5 \\
Aldehydes & 31 & 5.5 \\
Persulphates & 23 & 4.1 \\
Wood dust & 22 & 3.9 \\
Enzymes & 19 & 3.4 \\
Dust mite & 18 & 3.2 \\
Glues and resins & 15 & 2.7 \\
Mammals & 13 & 2.3 \\
Grain & 10 & 1.8 \\
Amines & 9 & 1.6 \\
Colophony & 8 & 1.4 \\
Acids & 7 & 1.3 \\
\hline
\end{tabular}

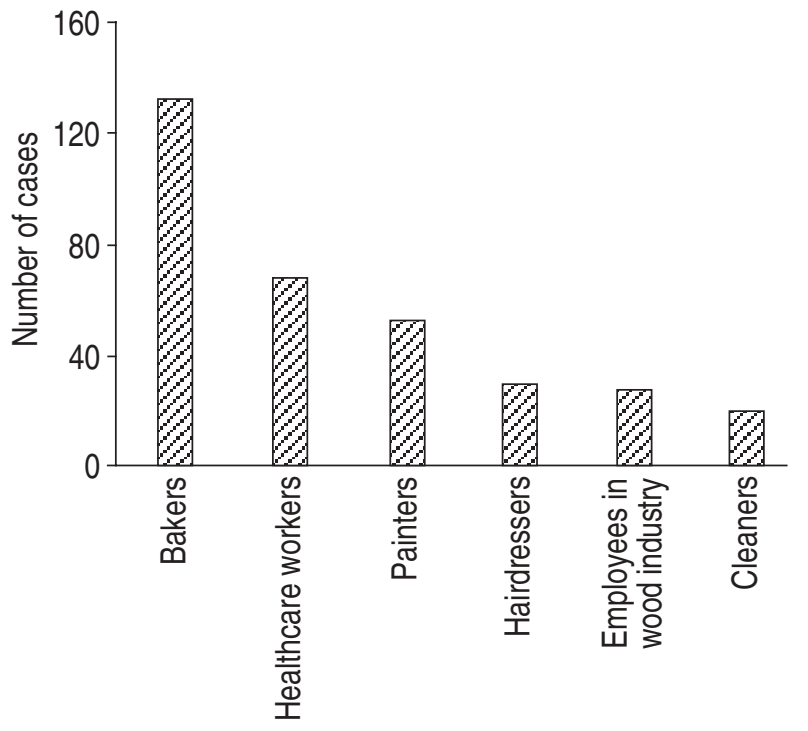

Occupations

Fig. 2.-Distribution of occupations in the Observatoire National des Asthmes Professionnels (ONAP) in 1997.

by PEFR or pulmonary function tests were performed in $33.3 \%$ and $23.9 \%$ of the cases, respectively. When pulmonary function tests were performed, $74.7 \%$ of PEFR were positive for work-related variations and $71.6 \%$ were positive for work related variations in the pulmonary function tests. Nonspecific hyperresponsiveness testing was performed in $53 \%$ of the cases and was positive in $82 \%$. To assess sensitization to the suspected agent, cutaneous tests and IgE measurements were carried out in $48.3 \%$ and $45.4 \%$ of the cases, respectively, and were positive in $73.3 \%$ and $59.4 \%$. Nasal and bronchial provocation tests to the specific aetiological agent were performed for $12 \%$ and $11 \%$ of the patients, respectively, and were positive for $68 \%$ and $77 \%$.

Characteristics of reporting physicians. One-third $(33 \%)$ of the cases were reported by chest physicians and/or allergists (private or hospital-based), but the majority came from occupational medicine departments and occupational physicians (67\%).

Claims to the National Health Service. Half the patients $(51.2 \%)$ put in a claim for workers' compensation for occupational asthma.

Incidence rate. Annual incidence rates were calculated per million workers in France (data from INSEE). The overall rate of occupational asthma was estimated at 25.7 cases per million workers. Considerable differences were found in the regional rates, from four per million workers in Auvergne to 73 per million workers in Alsace. Rates were also high in Ile-deFrance and Aquitaine (36 and 56 per million workers, respectively). 


\section{Discussion}

After the first complete year of voluntary reporting of occupational asthma in France by chest and occupational physicians, the answers of all the participants were compiled, including data from both the SPLF and SFMT members. Merging the two data files was required to eliminate double reported cases (nine cases). Preliminary results were presented in 1999 at the European Respiratory Society Meetings [10]. This confidential and voluntary reporting is still pursued and will provide interesting, findings about trends in the incidence of occupational asthma. Before ONAP began, information about the incidence of occupational asthma in France was available only through the claims awarding workers' compensation: $\sim 200$ cases were accepted annually [2]. In 1993, a questionnaire was sent out to occupational physicians to enquire about new cases of occupational asthma: of 385 cases reported, fewer than one third were awarded workers' compensation [2]. Another study in the south of France observed a similar underestimation of disability claims for occupational asthma [1].

The ONAP study measured the incidence of occupational asthma: 559 cases were reported in 1997, which corresponds to an annual rate of 25.7 per million workers. These results are very close to those of other surveillance schemes based on voluntary participation in Europe and North America: 19 per million workers in 1989 in the United Kingdom [3] and 37 per million for the period 1992-1993 [11], 24 per million workers in Italy [12], 25 per million workers in Quebec [13], 29 per million workers in the state of Michigan [7] for the period 1988-1994 (the rate remaining stable 1 yr later) [14].

Because these voluntary reports depend heavily on physician initiative, it would be expected that mandatory reporting would show higher incidence rates. This is indeed the case in Germany, where the reported rate is 51 per million workers, physicians in Germany are required to report suspected cases of occupational diseases to Trade-Assigned Statutory Accident Insurance Institutes [8]. The Finnish Institute of Occupational Health (FIOH) initiated the reporting of occupational diseases as early as 1964, significant compensation from insurance companies for therapy and rehabilitation as well as mandatory declaration of new cases increases the reliability of the Finnish data. Between 1986-1992, the number of new occupational asthma cases rose from 227 to 379 (annual rate $\sim 153$ cases per million workers $[9,15]$ ). ReIJULA et al. [15] explain this increase by improved diagnosis as well as by rising asthma incidence rates. In France, the ONAP results, even based on a voluntary reporting system, found double the number of new cases of occupational asthma awarded workers' compensation annually. Based on the results in Germany and Finland, the authors expect these numbers are but the "tip of an iceberg", to quote MEREDITH [16]. Estimations of incidence of work-related asthma could benefit from the application of new epidemiological methods [17]. For example, the capturerecapture method used by HENNEBERGER et al. [14] in Michigan resulted in an estimate that rose from 27 per million cases per year to between 58-240 per million cases per year.

The regional variation of incidence rates in the present study (rates ranging from 4-73 per million workers) is similar to the variations in the Surveillance of Work-Related and Occupational Respiratory Disease (SWORD) study (9-65 per million workers [16]) and in the Sentinel Event Notification System for Occupational Risks study (3-29 per million workers $[7,11])$. Several hypotheses may explain these variations: different levels of asthma symptom assessment and reporting, by both patients and physicians, and different risk levels, depending on local industry and occupational activities. Occupational asthma also appears at a high frequency in locations where leading research centres encourage physicians to give priority to its recognition and reporting. This might account for the high rates observed in Alsace, Ile-de-France and Aquitaine in France and in the West Midlands in the UK [6].

The aetiological findings cover only the first complete year of voluntary reporting of occupational asthma in France by ONAP. Therefore, it may be premature to make comparisons between these results and those published by surveillance schemes which have existed for a longer time. Moreover, variations concerning agents and occupations reported could also be related to the participation rates of the reporting physicians. Flour and isocyanates were the aetiologies most frequently reported. The frequency of flour-induced asthma was $23.3 \%$, which is similar to Finland (24.5\%) [11], but lower than Germany (37\%) [8]. Other studies report lower rates of flour induced asthma: $9 \%$ in the UK [18], 14\% in Quebec [13] and $<3 \%$ in Michigan and New Jersey [11].

Isocyanates are the first or second cause of occupational asthma in industrialized countries, accounting for 25\% of the cases in Quebec [13], 19\% in the USA [7], $15 \%$ in the UK $[11,18]$. The ONAP study found a very similar rate of $16.6 \%$. Latex occupies the third place in the ONAP study, with a rate of $7.5 \%$ among the 559 cases reported. This figure can be compared with the results obtained for the same year in the SWORD study (fourth place with a rate of $6.3 \%$ ) [19], which also showed a dramatic 10-fold increase in the incidence of this new agent between 1989 and 1997. A high proportion of occupational asthma was observed among hairdressers (5.2\%), essentially due to persulphates $(4.1 \%)$; this was also noted by BENA et al. [12]. Hair products are reported as aetiological agents more rarely in other surveillance schemes $(0.6 \%$ in Midland Society's Rare Respiratory Disease Registry Surveillance Scheme of Occupational Asthma (SHIELD) [6] and 1.0\% in SWORD [4]). Inversely, farmers were rarely reported to have occupational asthma; this may be due to the fact that in France their status is often that of independent workers, who have little possibility of obtaining compensation for occupational disabilities.

The sex distribution in this study was one-third female and two-thirds male. This ratio was also found in SHIELD and SWORD [6, 16]. However, this distribution differs in occupations that employ more males than females, as shown for bakers and 
pastry-cooks in France [20]. There was approximately the same incidence of occupational asthma in the older groups as in younger ones around $22-25 \%$ in each 10 -yr age group, except for the oldest patients (17\% for the 50-59-yr age group). If the same age groups are chosen as were used by FIOH (15-yr groups), the percentages are different from those found in Finland. The present study found a higher proportion of occupational asthma among the younger workers $(29 \%$ compared with $14 \%$ for the $15-29-\mathrm{yr}$ group), the same proportion for the 33-44-yr group (41\% in ONAP, $39 \%$ in the FIOH study), and for the oldest age group, lower rates were found $(27 \%$ in ONAP compared with $41 \%$ in FIOH study). This trend in France may be explained by age-related differences in occupation. However, the link between age and occupational asthma incidence is not easy to interpret and may involve numerous factors: the different proportions of workers in a given occupation in different age groups, variable exposure periods before onset of symptoms for different agents, intensity of exposure, time elapsed before diagnosis, etc.

The various studies estimating the incidence of occupational asthma do not all state which, if any, diagnostic tests led to the cases reported. Diagnosis of occupational asthma, often difficult, is facilitated by the combination of several diagnostic tests. The present study included an evaluation of the accuracy of diagnostic procedures performed by the physicians. Although $80 \%$ of the physicians said that their diagnosis was "certain" or "probable" and asserted that the symptoms were work related in $92 \%$ of the cases, PEFR measurements were made in only $33 \%$ of the cases; for chest physicians, this percentage reached $46 \%$. In the one other scheme that reported the methods of diagnosis, the frequency was nearly the same for general chest physicians $(50 \%)$ [6]. Bronchialspecific challenges appear to have been performed rarely: $11.1 \%$ in this study, and $10-12 \%$ in the SHIELD scheme [6]. When these tests were performed, very often both were positive $(75 \%$ for PEFR variation and $77 \%$ for specific bronchial provocation tests). In France, the compensation legislation does not necessarily demand objective confirmation of the diagnosis of occupational asthma induced by officially-accepted offending agents. Thus, this may partly explain the low frequency of PEFR measurements and specific bronchial challenge tests. Nonspecific bronchial hyperresponsiveness testing was performed in half of the cases, with positive results in $82 \%$. This is in accordance with the high frequency of hyperresponsiveness in patients with occupational asthma such as that observed with isocyanates in the present study [21]. The study found that a relatively high frequency of tests was performed to detect immunological sensitization, especially in occupational asthma caused by high molecular weight allergens.

Because of the considerable bias inherent in a surveillance system based on voluntary reporting, the number of cases of occupational asthma reported is probably lower than the real incidence. Nonetheless, Observatoire National des Asthmes Professionnels fostered physician awareness of occupational asthma and has yielded useful estimates of occupational asthma incidence and aetiologies in France. It also enabled comparisons with other surveillance schemes, revealed common problems such as isocyanates and flour, which are frequent offending agents, and detected specific information about newly-emerging aetiological agents.

Members of Observatoire National des Asthmes Professionnels group: G. Arnaud, A. Bergeret, M. Blaumeiser, F. de Blay, L. Boitel, C. Bonnin, P. Brochard, J. Brun, C. Cabal, B. Cador, D. Caillaud, A. Cantineau, J. Chazenfus, D. Choudat, F. Conso, S. Costes, M. Couot, J.P. Curtes, J.C. Dalphin, D. Danaud, Ph. Danjou, B. Delemotte, F. Deschamps, J.W. Dewitte, A. Didier, C. Doutrellot-Philippon, F. Dufresne-Benetti, D. Dumont, D. Dupas, D. Faucon, J.L. Fumery, D. Gabrillargues, R. Garnier, P. Godard, E. Grudzien, J.M. Hémery, B. Javelaud, G. Lasfargues, B. Leleu, M. Letourneux, B. Libert, J. Loriot, F. Martin, M.P. Michel, C. Nisse, C. Paris, J.C. Pairon, D. Penneau-Fontbonne, A. Perdrix, G. Petiet, P. Pommier de Santi, H. Robin, M. Saadjian, H.J. Smolik, J.M. Soulat, C. Tarin, D. Terracol, C. Teyssier-Cotte, J.M. Tunon de Lara.

Acknowledgements. The authors gratefully acknowledge contributions to this project by the participating physicians.

\section{References}

1. Lagier F, Martin F, Charpin D, Vervloet D. Sous-déclaration des cas d'asthme professionnel dans la région Provence-Alpes-Côte d'Azur et la Corse. Rev Mal Resp 1991; 8: 209-212.

2. Ameille J. Les asthmes professionnels: données épidémiologiques et résultats de 1 'enquête nationale. Arch Mal Prof 1996; 57: 75-77.

3. Meredith S, Taylor VM, McDonald JC. Occupational respiratory disease in the United Kingdom 1989: a report to the British Thoracic Society and the Society of Occupational Medicine by the SWORD project group. Br J Ind Med 1991; 48: 292-298.

4. Meredith S, McDonald JC. Work-related respiratory disease in the United Kingdom, 1989-92: report in the SWORD project. Occup Med 1994; 44: 183-189.

5. Gannon PFC, Burge PS. A preliminary report of the surveillance scheme of occupational asthma in the West Midlands. Br J Ind Med 1991; 48: 579-582.

6. Gannon PFG, Burge PS. The SHIELD scheme in the West Midlands Region United Kingdom. $\mathrm{Br} J$ Ind Med 1993; 50: 791-796.

7. Rosenmann KD, Reilly MJ, Kalinowski DJ. A statebased surveillance system for work-related asthma. J Occup Environ Med 1997; 39: 415-425.

8. Baur X, Degens P, Weber K. Occupational obstructive airway diseases in Germany. Am J Ind Med 1998; 33 : $454-461$.

9. Keskinen H, Alanko K, Saarinen L. Occupational asthma in Finland. Clin Allerg 1978; 8: 569-579.

10. Kopferschmitt-Kubler MC, Popin E, CalastrengCrinquand $\mathrm{A}$, et al. Occupational asthma in France 
(1997): a report of the ONAP project. Eur Respir $J$ 1999; 14: Suppl. 30, 66s.

11. Meredith S, Nordman H. Occupational asthma: measures of frequency from four countries. Thorax 1996; 51: 435-440.

12. Bena A, D'Errico A, Mierabelli D. A system for the active surveillance of occupational bronchial asthma the results of two years of activity of the PRIOR program. Medicina del Lavoro 1990; 90: 556-571.

13. Lagier F, Cartier A, Malo JL. Statistiques médicolégales sur 1'asthme professionnel au Québec de 1986 à 1988. Rev Mal Respir 1990; 7: 337-341.

14. Henneberger PK, Kreiss K, Rosenman KD, Reilly MJ, Chang YF, Geidenberger CA. An evaluation of the incidence of work-related asthma in the United States. Int J Occup Environ Health 1999; 5: 1-8.

15. Reijula K, Haahtela T, Klaukka T, Rantanen J. Incidence in occupational asthma and persistent asthma in young adults has increased in Finland. Chest 1996; 110: 58-61.

16. Meredith S. Reported incidence of occupational asthma in the United Kingdom, 1989-90. J Epidemiol Community Health 1993; 47: 459-463.

17. Hook EB, Regal RR. Capture-recapture methods in epidemiology: methods and limitations. Epidemiol Rev 1995; 17: 243-264.

18. Ross DJ, Keynes HL, MeDonald JC. SWORD '96: surveillance of work-related and occupational respiratory disease in the UK. Occup Med 1997; 47: $377-$ 381.

19. Ross DJ, Keynes HL, McDonald JC. SWORD '97: surveillance of work-related and occupational respiratory disease in the UK. Occup Med 1998; 48: 481-485.

20. Ameille J, Mariel D, Pauli G, et al. Features of occupational asthma in bakers and pastrycooks in France. Eur Respir J 1999; 14: Suppl. 30, 536s.

21. Pauli G, Kopferschmitt MC. Isocyanates and asthma. In: Miyamoto T, Okuda M, eds. Progress in Allergy and Clinical Immunology. Proceedings of the 14th International Congress of Allergology and Clinical Immunology, Kyoto, 1991. Toronto, Hogrefe \& Huber, 1992; pp. 152-158. 